\title{
Retinal vascular fractal dimension in bipolar disorder and schizophrenia
}

Citation for published version (APA):

Appaji, A., Nagendra, B., Chako, D. M., Padmanabha, A., Hiremath, C. V., Jacob, A., Varambally, S., Kesavan, M., Venkatasubramanian, G., Rao, S. V., Webers, C. A. B., Berendschot, T. T. J. M., \& Rao, N. P. (2019). Retinal vascular fractal dimension in bipolar disorder and schizophrenia. Journal of Affective

Disorders, 259, 98-103. https://doi.org/10.1016/j.jad.2019.08.061

Document status and date:

Published: 01/12/2019

DOI:

10.1016/j.jad.2019.08.061

Document Version:

Publisher's PDF, also known as Version of record

Document license:

Taverne

Please check the document version of this publication:

- A submitted manuscript is the version of the article upon submission and before peer-review. There can be important differences between the submitted version and the official published version of record.

People interested in the research are advised to contact the author for the final version of the publication, or visit the DOI to the publisher's website.

- The final author version and the galley proof are versions of the publication after peer review.

- The final published version features the final layout of the paper including the volume, issue and page numbers.

Link to publication

\footnotetext{
General rights rights.

- You may freely distribute the URL identifying the publication in the public portal. please follow below link for the End User Agreement:

www.umlib.nl/taverne-license

Take down policy

If you believe that this document breaches copyright please contact us at:

repository@maastrichtuniversity.nl

providing details and we will investigate your claim.
}

Copyright and moral rights for the publications made accessible in the public portal are retained by the authors and/or other copyright owners and it is a condition of accessing publications that users recognise and abide by the legal requirements associated with these

- Users may download and print one copy of any publication from the public portal for the purpose of private study or research.

- You may not further distribute the material or use it for any profit-making activity or commercial gain

If the publication is distributed under the terms of Article $25 \mathrm{fa}$ of the Dutch Copyright Act, indicated by the "Taverne" license above, 
Research paper

\title{
Retinal vascular fractal dimension in bipolar disorder and schizophrenia
}

\author{
Abhishek Appaji $^{\mathrm{a}, \mathrm{c}, 1}$, Bhargavi Nagendra ${ }^{\mathrm{b}, 1}$, Dona Maria Chako ${ }^{\mathrm{b}}$, Ananth Padmanabha ${ }^{\mathrm{a}}$, \\ Chaitra V. Hiremath ${ }^{\mathrm{b}}$, Arpitha Jacob ${ }^{\mathrm{b}}$, Shivarama Varambally ${ }^{\mathrm{b}}$, Muralidharan Kesavan ${ }^{\mathrm{b}}$, \\ Ganesan Venkatasubramanian $^{\mathrm{b}}$, Shyam Vasudeva Rao ${ }^{\mathrm{a}, \mathrm{c}}$, Carroll A.B. Webers ${ }^{\mathrm{c}}$, \\ Tos T.J.M. Berendschot ${ }^{\mathrm{c}}$, Naren P. Rao ${ }^{\mathrm{b}, *}$ \\ ${ }^{a}$ Department of Medical Electronics, B.M.S. College of Engineering, Bangalore, India \\ ${ }^{\mathrm{b}}$ Department of Psychiatry, National Institute of Mental Health and Neurosciences, Bangalore, India \\ ${ }^{\mathrm{c}}$ University Eye Clinic Maastricht, Maastricht University, Maastricht, The Netherlands
}

\section{A R T I C L E I N F O}

\section{Keywords:}

Retinal vasculature

Fractal dimension

Fundus

Schizophrenia

Bipolar disorder

Psychoses

Neurodevelopment

\begin{abstract}
A B S T R A C T
Background: Bipolar disorder (BD) and schizophrenia (SCZ), are associated with greater vascular co-morbidities and adverse vascular events. Owing to shared developmental origins and morphology, retinal vasculature is a proxy assessment measure of the cerebral vasculature. Although retinal vascular fractal dimension $\left(D_{f}\right)$, a measure of vascular geometry and complexity of branching, has been shown to be directly associated with cerebrovascular pathology, it has not been examined in SCZ and BD.

Methods: We studied 277 participants ( 92 healthy volunteers, 98 SCZ, and 87 BD) from 18 to 50 years of age. Images were acquired by trained personnel using a non-mydriatic fundus camera and the retinal vascular $\mathrm{D}_{\mathrm{f}}$ was calculated by the box-counting method using an automated algorithm. The average $\mathrm{D}_{\mathrm{f}}$ across the left and right eyes were calculated.

Results: Both SCZ and BD had significantly increased $\mathrm{D}_{\mathrm{f}}$ compared to HV despite controlling for possible confounding factors. However, there was no significant difference between SCZ and BD. These findings suggest abnormal retinal vascular $\mathrm{D}_{\mathrm{f}}$ in psychoses.

Limitations: The study design was cross-sectional, and patients were on medications. Confound of lifestyle factors such as diet and exercise, if any, was not controlled. Sub-group analysis between BD-I and BD-II was not performed in view of the small sample.

Conclusions: Considering the easy accessibility, affordability, and non-invasive nature of the examination, retinal vascular $\mathrm{D}_{\mathrm{f}}$ could serve as a surrogate marker for cerebral vascular abnormality and could potentially identify BD and SCZ patients at risk of developing adverse vascular events.
\end{abstract}

\section{Introduction}

The major psychoses, schizophrenia (SCZ) and bipolar disorder (BD), are associated with increased prevalence of vascular co-morbidities and increased incidence of adverse cerebrovascular events (Correll et al., 2017; Goldstein, 2017). Understandably, examination of cerebral microvascular abnormalities in these disorders has gained considerable interest in the recent past. However, the need for specialized and expensive techniques, and the invasive nature of some of these techniques have posed challenges for the same (Lavina, 2016).

As retinal and cerebral vasculatures share common embryology and have comparable anatomical, physiological, and pathological properties, retinal vasculature is considered an indirect marker of abnormalities in cerebral vasculature (Patton et al., 2005; Wong et al., 2001). Several studies have reported relations of retinal vascular abnormalities with cerebrovascular disorders and neurodegenerative disorders (Cabrera DeBuc et al., 2017; Moss, 2015). A few studies have examined retinal vascular abnormalities in psychoses. In one of these, authors examined retinal vascular images from participants of the Dunedin birth cohort and reported wider venules in individuals who developed schizophrenia (Meier et al., 2013). In another study, those with symptoms of psychosis and their unaffected co-twins had wider venular diameters compared to the healthy, suggesting association of retinal venular diameter with familial vulnerability to psychosis (Meier et al.,

\footnotetext{
* Corresponding author.

E-mail address: docnaren@gmail.com (N.P. Rao).

${ }^{1}$ Both authors contributed equally to the manuscript.
} 
2015). Compared to SCZ, retinal vascular abnormalities are underexamined in BD; one study reported absence of difference between $\mathrm{BD}$ and healthy volunteers (HV) but reported a significant association of the arterio-venular ratio (AVR) with blood pressure and vascular endothelial function in adolescent BD (Naiberg et al., 2017). Recently, we reported both SCZ and BD patients to have significantly narrower arterioles and wider venules compared to HV (Appaji et al., 2019).

All these studies examined retinal vascular calibre. Yet another important structural marker, fractal dimension $\left(D_{f}\right)$, has not been examined in SCZ or BD. Larger blood vessels, including retinal blood vessels, subdivide into smaller branches which in turn also subdivide and so on. This self-similar branching pattern is quantified by a mathematical concept called fractals. Fractals were introduced to ophthalmology (Family et al., 1989) as retinal vasculature is similar on all kinds of scales from the larger vessels coming from the optic disc till the microvasculature near fovea. Hence, this complex branching pattern of retinal vasculature is better quantified by $D_{f}$ than conventional geometrical measures (Mainster, 1990). $\mathrm{D}_{\mathrm{f}}$ is a single value that indicates the degree of branching complexity of blood vessels (Lim et al., 2009; Masters, 2004). $D_{f}$ depends on the number of bifurcations, angles of bifurcations, and the length of vessels between two successive bifurcations (Liew et al., 2008). A higher $D_{f}$ indicates a greater level of complexity in retinal branching pattern and lower $\mathrm{D}_{\mathrm{f}}$ indicates absence or decrease in number of branches. Importantly, retinal vascular $D_{f}$ measure is not affected by pulse cycle which may confound the measurement of vascular calibre (Lavina, 2016). Moreover, variations in the ocular and camera magnifications could influence the retinal vessel calibre values but not $D_{f}$ (Cheung et al., 2007). It is important to note that several studies have reported association of retinal vascular $D_{f}$ with diabetes and diabetic retinopathy, hypertension, cardiovascular disorder, stroke, and dementia (Cheung et al., 2010; Doubal et al., 2010; Huang et al., 2016; Kim et al., 2011; Lesage et al., 2009; McGrory et al., 2017; Popovic et al., 2018; Wong et al., 2002).

However, despite its significance, retinal vascular $\mathrm{D}_{\mathrm{f}}$ in SCZ and BD is yet to be examined. Hence, we aimed to investigate retinal vascular $\mathrm{D}_{\mathrm{f}}$ in SCZ and BD. Based on the existing literature, we hypothesized that patients with SCZ and BD would have increased retinal vascular $D_{f}$ when compared to HV. As both SCZ and BD are associated with increased vascular morbidity and have shared pathogenic mechanisms, we also hypothesized that there would be no difference in $D_{f}$ between SCZ and BD.

\section{Methodology}

\subsection{Study participants}

One hundred patients each with SCZ and BD were recruited from the clinical services of the National Institute of Mental Health and Neurosciences (NIMHANS), Bengaluru, India. One hundred matched healthy volunteers (HV) were also recruited from the same geographical location through flyers and word of mouth. All participants were aged between 18 and 50 years. The patients were examined by a board-certified psychiatrist (BN); and those who met the criteria for SCZ or BD as per the International Classification of disorders 10 (ICD10) (WHO, 1992) were recruited. Patients with substance abuse or dependence other than nicotine were excluded. Those with concurrent comorbid psychiatric disorders were also excluded. All HV completed self-reported cross cutting symptom measure (Narrow et al., 2013) and were interviewed by a certified psychiatrist (BN) to rule out Axis I psychiatric diagnoses. Participants with history of hypertension, diabetes, stroke, and trauma or surgery to the eye were excluded from the study. The study was carried out in accordance with the latest version of the Declaration of Helsinki. Written informed consent was obtained from all participants and the study was approved by the institute ethics committee.

\subsection{Clinical assessments}

The severity of clinical symptoms was assessed by a board certified psychiatrist using the Brief Psychiatric Rating Scale (BPRS) in patients with SCZ (Overall and Gorham, 1962), and Young Mania Rating Scale (Young et al., 1978) and Hamilton Depression Rating Scale (HDRS) (Hamilton, 1960) in patients with BD. The global severity and functioning was assessed using the Clinical Global Impression (CGI) (Busner and Targum, 2007) and Global Assessment of Functioning (GAF) (Jones et al., 1995). To control for the potential confounding effect of systolic blood pressure and body mass index (BMI) on retinal vascular $\mathrm{D}_{\mathrm{f}}$, we measured the same in a subgroup of individuals; systolic blood pressure was measured in $28 \mathrm{SCZ}$ and $57 \mathrm{BD}$ and BMI was measured in $48 \mathrm{HV}, 81 \mathrm{SCZ}$ and $60 \mathrm{BD}$ on the day of acquisition of retinal images.

\subsection{Retinal image acquisition}

The procedure of retinal image acquisition was explained to all participants. They were seated in a dark room for approximately 5 min to enable auto-dilation of the pupil through accommodation. The images were acquired using a non-mydriatic fundus camera, the 3nethra classic by a trained individual. The 3nethra fundus camera illuminates the eye using light flashes to obtain colour images of the fundus. Optic disc centred retinal images of both the eyes were acquired using a valid method described elsewhere (Nguyen et al., 2010).

\subsection{Measurement of retinal vascular fractal dimension}

An initial quality check was performed to examine the suitability of images for calculation of the fractal dimension. Twenty-three out of 300 image pairs (left and right eye) were excluded following quality check due to inadequate illumination; the remaining 277 image pairs were considered for analysis. These included 98 SCZ, 87 BD, and 92 HV. A fully automated software was designed to calculate $D_{f}$ using MATLAB 2018a (The MathWorks Inc, Natick, Massachusetts, USA). The algorithm used to design this customized software was adopted from previous studies and employed the box-counting method described elsewhere (Cheung et al., 2012; Zhu et al., 2014). Examination of retinal vascular $\mathrm{D}_{\mathrm{f}}$ is an advancing field and novel analyses techniques are rapidly emerging (Cheung et al., 2009; Kostic et al., 2018; Talu et al., 2015). We opted for the box-counting method as it is one of the commonly employed methods.

The following is a brief overview. The image was first enhanced in terms of intensity to aid extraction of the vessels. The acquired retinal images had a spatial resolution of $2048 \times 1536$ pixels and they were suitably scaled for easy calculation of fractal dimension. The measured area was standardized within the region between 0.5 and 2.0-disc diameters from the optic disc. The retinal vessels (both arteries and veins) were automatically traced and segmented to generate a skeletonized image. We calculated the fractal dimension using the boxcounting dimension method. In the box counting method, the retinal image was divided into multiple equally sized square boxes. The number of boxes containing the skeletonized line tracing was counted and the process was repeated for different sized squares. The fractal dimension $\left(D_{f}\right)$ was calculated as the gradient of logarithms of the number of boxes and the size of the boxes. Larger values of $D_{f}$ indicate more complex branching patterns. $\mathrm{D}_{\mathrm{f}}$ was calculated for left and right eyes separately; the average of left and right eye $D_{f}$ was used as the primary outcome measure in the study. The calculation of $D_{f}$ was completely automated; hence, group bias did not confound the analysis (HV or SCZ or BD).

\subsection{Statistical analysis}

The statistical analyses were performed using the Statistical Package 
for Social Sciences (SPSS) version 25 (SPSS Inc., Chicago, Illinois, USA). The data was found to be normatively distributed on applying the Shapiro-Wilk test and hence, parametric tests were applied. The age difference across the three groups was examined using one-way analysis of variance (ANOVA) and the sex distribution using chi-square test. As the age and sex distribution were not similar across the three groups and these were used as covariates for further analyses. Differences in $D_{f}$ across the three groups were examined using analysis of co-variance (ANCOVA) with age and sex as covariates. Bonferroni post-hoc analysis was conducted to examine differences between pairs of groups. To examine the relation between $\mathrm{D}_{\mathrm{f}}$ and clinical variables, Pearson's correlational analyses were performed for $\mathrm{D}_{\mathrm{f}}$ with scores on BPRS, YMRS, and HDRS, age at onset of illness, duration of illness, and chlorpromazine equivalent of antipsychotic dose (Woods, 2003).

To calculate the extent of contribution of age and sex on $D_{f}$, we also conducted linear regression analysis with $\mathrm{D}_{\mathrm{f}}$ as dependent variable and group, age, and sex as predictor variables. As a subgroup of patients had nicotine dependence, analysis was repeated after excluding these patients to avoid the possible confounding effect of nicotine use on retinal vascular $\mathrm{D}_{\mathrm{f}}$ (Yanagi et al., 2014). In addition, to rule out the confounding effects of BMI and systolic blood pressure, analysis was also conducted in another sub-group of patients in whom these had been recorded.

\section{Results}

\subsection{Comparison of demographic variables}

Demographic and clinical variables from the three groups are shown in Table 1. There was a significant difference across the three groups in age and sex distribution. Duration of illness and age at onset of illness were not significantly different in patients with SCZ and BD.

\subsection{Differences in $D_{f}$ between groups}

On ANCOVA, there was a significant difference across the three groups in left eye $\mathrm{D}_{\mathrm{f}}(p<0.001)$, right eye $\mathrm{D}_{\mathrm{f}}(p=0.003)$, and average $\mathrm{D}_{\mathrm{f}}(p<0.001)$ (Table 2). Further post-hoc analysis showed that both SCZ (left eye $D_{f}=0.015$; right eye; $D_{f}=0.006$; average $D_{f}=0.001$ ) and BD (left eye $D_{f}<0.001$; right eye $D_{f}=0.003$; average $D_{f}$ $p<0.001$ ) had significantly higher $\mathrm{D}_{\mathrm{f}}$ compared to HV; however, there was no significant difference between SCZ and BD $(p>0.05)$ (Table 3 and Fig. S1).

To calculate the extent of contribution of age and sex and to delineate their possible confounding effects on group wise comparisons, regression analyses were conducted with and without age and sex as additional regressors. The group differences were significant in both instances and the regression coefficients were comparable, suggesting that age and sex did not have any significant effects (Table 4). We also conducted a subgroup analysis with a sample of $66 \mathrm{HV}(\mathrm{M}: \mathrm{F}=32: 34$; age $=30.4 \pm 6.0$ years), $92 \mathrm{SCZ}(\mathrm{M}: \mathrm{F}=60: 32$; age $=32.4 \pm 5.3$ years) and $78 \mathrm{BD}(\mathrm{M}: \mathrm{F}=50: 28$; age $=32.53 \pm 5.2$ years $)$ matched on age $(F=2.33 ; p=0.10)$ and $\operatorname{sex}\left(\chi^{2}=5.3 ; p=0.073\right)$. On ANOVA, there was still a significant difference across the three groups on $D_{\mathrm{f}}$ ( $F=7.88, p<0.001$ ) (details in Supplementary Table S1). As 17 patients (13 SCZ and $4 \mathrm{BD}$ ) had nicotine dependence, we compared the groups after excluding these patients to rule out possible confounding effects of nicotine use. There was still a significant difference between groups on left eye $D_{f}$, right eye $D_{f}$, and average $D_{f}$ (details in Supplementary Tables S2A and S2B). In a sub-group of participants, we had measured BMI and recorded blood pressure on the day of retinal image acquisition. ANCOVA and regression analysis with BMI and blood pressure as a covariate demonstrated that the results were still significant (details in Supplement S3 and Supplementary Tables S4 and S5).

\subsection{Relation between clinical variables and retinal vascular $D_{f}$}

Pearson's correlational analysis showed no significant correlation between the $D_{f}$ and clinical variables (BPRS score, YMRS score, HDRS score, age at onset of illness, duration of illness, and CPZ equivalent of antipsychotic dose) $(p>0.05)$ (Supplementary Table S6).

\section{Discussion}

Ours is the first study to examine retinal vascular $\mathrm{D}_{\mathrm{f}}$ in SCZ and BD in comparison with HV. Results of our study shows increased $\mathrm{D}_{\mathrm{f}}$ in both $\mathrm{BD}$ and SCZ when compared to HV. As hypothesized, there was no significant difference between SCZ and BD in the same. Importantly, the findings remained significant even after controlling for potential confounding factors. There was no significant relation with clinical severity suggesting the possibility that $\mathrm{D}_{\mathrm{f}}$ may be independent of ongoing psychopathology.

Our findings further add to the existing research demonstrating abnormal retinal vascular calibre in SCZ and BD (Appaji et al., 2019; Meier et al., 2015; Meier et al., 2016). We sought to examine retinal vascular $D_{f}$ as several previous studies have reported that the geometric parameters of retinal vasculature, such as the bifurcation angle, number of bifurcations, and length to diameter ratio, are also related to vascular disease processes and could prove to be potential markers of microvascular pathology (Patton et al., 2007; Witt et al., 2006). Although the measurement of retinal vascular $\mathrm{D}_{\mathrm{f}}$ is more complicated and challenging, it offers several advantages (Huang et al., 2016); (a) It is not influenced by the phase of the pulse cycle; pulse to pulse variations may pose problems during vascular calibre measurement. (b) It is also independent of other confounding factors like axial length and camera magnification that could influence retinal vessel calibre values. (c) $D_{f}$ measurement does not involve assessing individual vessels unlike vessel calibre (Cheung et al., 2007; Knudtson et al., 2004; Lavina, 2016). Hence, $D_{f}$ is considered a suitable measure to study individuals longitudinally and across centres in multicentric studies.

Several studies have reported association of increased $D_{f}$ with systemic and cerebrovascular pathologies; increased $D_{f}$ is independently associated with lacunar stroke after adjusting for age, sex, other

Table 1

Comparison of demographic and clinical details between the groups.

\begin{tabular}{|c|c|c|c|c|c|}
\hline & $\mathrm{HV}(n=92)$ & $\operatorname{SCZ}(n=98)$ & $\mathrm{BD}(n=87)$ & $F / t / \chi^{2}$ & $p$ \\
\hline Age & $30.2 \pm 7.8$ & $32.7 \pm 6$ & $32.9 \pm 6$ & 4.54 & 0.012 \\
\hline Gender ratio (M/F) & $41 / 51$ & $64 / 34$ & $54 / 33$ & 9.48 & 0.009 \\
\hline Age at onset (years) & - & $25.1 \pm 5.3$ & $23.7 \pm 5.9$ & 2.58 & 0.11 \\
\hline Duration of illness (in years) & - & $7.6 \pm 5.1$ & $9.0 \pm 5.6$ & 2.3 & 0.13 \\
\hline BPRS & - & $28.7 \pm 6.9$ & - & - & - \\
\hline HDRS & - & - & $3.9 \pm 5.3$ & - & - \\
\hline YMRS & - & - & $1.9 \pm 3.1$ & - & - \\
\hline
\end{tabular}

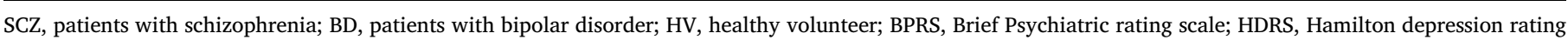
scale; YMRS, Young's mania rating scale; $F$, analysis of variance; $t$, independent $t$ test; $\chi^{2}$, Chi square test. 
Table 2

Retinal vascular fractal dimension across the three groups.

\begin{tabular}{|c|c|c|c|c|c|}
\hline Fractal dimension & $\mathrm{HV}(n=92)$ & $\operatorname{SCZ}(n=98)$ & $\mathrm{BD}(n=87)$ & $F$ & $p$ \\
\hline Left $D_{f}$ & $1.281 \pm 0.096$ & $1.321 \pm 0.093$ & $1.339 \pm 0.01$ & 6.08 & $<0.001$ \\
\hline Right $\mathrm{D}_{\mathrm{f}}$ & $1.266 \pm 0.082$ & $1.31 \pm 0.089$ & $1.316 \pm 0.123$ & 4.05 & 0.003 \\
\hline Average $D_{f}$ & $1.273 \pm 0.081$ & $1.316 \pm 0.069$ & $1.327 \pm 0.087$ & 7.52 & $<0.001$ \\
\hline
\end{tabular}

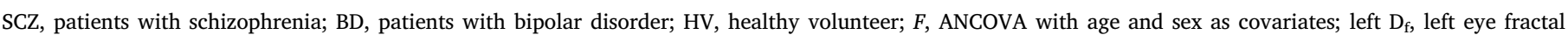
dimension; right $\mathrm{D}_{\mathrm{f}}$, right eye fractal dimension; $\mathrm{D}_{\mathrm{f}}$, average fractal dimension.

Table 3

Post-hoc analysis showing group differences in retinal vascular fractal dimension.

\begin{tabular}{llllll}
\hline Fractal dimension & Group & & Mean difference & Std. error & $p$ \\
\hline \multirow{2}{*}{ Left $\mathrm{D}_{\mathrm{f}}$} & HV & SCZ & -0.039 & 0.014 & 0.015 \\
& HV & BD & -0.058 & 0.014 & $<0.001$ \\
\multirow{2}{*}{ Right $\mathrm{D}_{\mathrm{f}}$} & SCZ & BD & -0.019 & 0.014 & 0.568 \\
& HV & SCZ & -0.045 & 0.014 & 0.006 \\
& HV & BD & -0.05 & 0.015 & 0.003 \\
Average $\mathrm{D}_{\mathrm{f}}$ & SCZ & BD & -0.01 & 0.015 & 1.000 \\
& HV & SCZ & -0.042 & 0.011 & 0.001 \\
& HV & BD & -0.054 & 0.012 & $<0.001$ \\
& SCZ & BD & -0.012 & 0.012 & 0.917 \\
\hline
\end{tabular}

SCZ, patients with schizophrenia; BD, patients with bipolar disorder; HV, healthy volunteer; $p$, Bonferroni post-hoc analysis; left $\mathrm{D}_{\mathrm{f}}$, left eye fractal dimension; right $\mathrm{D}_{\mathrm{f}}$, right eye fractal dimension; $\mathrm{D}_{\mathrm{f}}$, average Fractal dimension; $p$, Bonferroni post-hoc analysis.

vascular risk factors (Cheung et al., 2010), diabetes (Yau et al., 2010), and early diabetic retinopathy (Cheung et al., 2009). However, few studies have reported discrepant findings (Aliahmad et al., 2014; Kawasaki et al., 2011). As $\mathrm{D}_{\mathrm{f}}$ varies significantly based on the method used for analysis, differences in technique could account for these discrepancies (Huang et al., 2016). The finding of a positive association between retinal vascular $D_{\mathrm{f}}$ and white matter hyperintensities provides direct evidence that retinal vascular $\mathrm{D}_{\mathrm{f}}$ could be a proxy measure of cerebral vasculature abnormalities (van de Kreeke et al., 2018). In the background of these studies, our findings could have important implications in SCZ and BD. In conjunction with several other studies along similar lines of research, (Appaji et al., 2019; Correll et al., 2017; Goldstein, 2017; Hudson et al., 1997; Mathew et al., 1988; Meier et al., 2016; Rubin et al., 1995; Sun et al., 2009) our findings of altered $D_{f}$ suggest increased risk of adverse vascular events in SCZ and BD. While all patients with BD and SCZ are at risk of developing an adverse vascular event, a few may be at greater risk and it is important to identify these individuals to initiate preventive interventions. Interestingly, retinal vascular Df is shown to be associated with increased risk of adverse vascular events in previous studies (Cheung et al., 2009; Cheung et al., 2010; Yau et al., 2010). Considering the affordability and easy accessibility of retinal imaging, retinal microvascular $D_{f}$ examination could serve as a potential screening tool to identify individuals at risk for adverse vascular events. Future studies need to prospectively examine whether retinal vascular $\mathrm{D}_{\mathrm{f}}$ has the potential to identify individuals with SCZ and BD at greater risk of development of adverse vascular events.

The reason for increased retinal vascular $\mathrm{D}_{\mathrm{f}}$ in $\mathrm{BD}$ and SCZ is not completely known at this stage. An important factor influencing the retinal vascular branching pattern is tissue hypoxia. Optimally timed hypoxia is critical during normal development of retinal vasculature and tissue architecture, but ill-timed hypoxia can result in the pathological changes seen in proliferative diabetic retinopathy, retinopathy of prematurity, and wet form of age-related macular degeneration (Grimm and Willmann, 2012). Thus, an increased $\mathrm{D}_{\mathrm{f}}$ could result from either early developmental or late life causes. The underlying mechanisms for increased $\mathrm{D}_{\mathrm{f}}$ in SCZ and BD are not completely known. Considering the increased prevalence of metabolic syndrome and adverse vascular events in SCZ and BD (Correll et al., 2017; Goldstein, 2017), it is possible that these adverse metabolic risk factors remodel the retinal vascular pattern. However, perinatal hypoxia which has been implicated in psychoses (Brixey et al., 1993; Clarke et al., 2006) could also have influenced the retinal vascular branching pattern Our study being cross-sectional, it is not possible to rule out either of these reasons. A longitudinal study using a birth cohort could provide further insights.

Several studies in the recent past have suggested shared risk factors and considerable overlap between pathophysiological processes in SCZ and BD (Craddock and Owen, 2010). Considering the common developmental origin of these disorders and the significant vascular comorbidity in both, we expected similarities in retinal vascular $D_{f}$ also. Previous studies have reported considerable overlap between BD-I and SCZ in neuroimaging, electrophysiological measures, and susceptibility genes (Craddock and Owen, 2010; Tamminga et al., 2013). Hence, our finding of no significant difference between SCZ and BD in $\mathrm{D}_{\mathrm{f}}$ is in accordance with the recent literature suggesting overlap between the two disorders. However, future studies are required as our recent study suggested significant difference between SCZ and BD in retinal vascular calibre (Appaji et al., 2019). We did not find any relation between retinal vascular $D_{f}$ and severity of clinical variables. However, as all patients were on medications and the study design was cross sectional, our findings need to be considered preliminary and longitudinal studies

Table 4

Mean difference of retinal fractal dimension between groups adjusted for age and sex.

\begin{tabular}{|c|c|c|c|c|c|c|}
\hline Variable & Group & & $\begin{array}{l}\text { Not adjusted for age and sex } \\
\beta(95 \% \mathrm{CI})\end{array}$ & $p$ & $\begin{array}{l}\text { Adjusted for age and sex } \\
\beta(95 \% \mathrm{CI})\end{array}$ & $p$ \\
\hline \multirow[t]{3}{*}{ Left $D_{f}$} & $\mathrm{HV}$ & SCZ & $0.192(0.012$ to 0.067$)$ & 0.005 & 0.234 (0.02 to 0.076$)$ & 0.001 \\
\hline & $\mathrm{HV}$ & $\mathrm{BD}$ & $0.274(0.03$ to 0.086$)$ & $<0.001$ & $0.312(0.037$ to 0.095$)$ & $<0.001$ \\
\hline & SCZ & $\mathrm{BD}$ & $0.088(-0.009$ to 0.046$)$ & 0.189 & $0.085(-0.01$ to 0.046$)$ & 0.199 \\
\hline \multirow[t]{3}{*}{ Right $D_{f}$} & $\mathrm{HV}$ & SCZ & $0.212(0.017$ to 0.073$)$ & 0.002 & $0.234(0.02$ to 0.079$)$ & 0.001 \\
\hline & $\mathrm{HV}$ & $\mathrm{BD}$ & $0.230(0.021$ to 0.079$)$ & 0.001 & 0.249 (0.024 to 0.084$)$ & $<0.001$ \\
\hline & SCZ & $\mathrm{BD}$ & $0.024(-0.024$ to 0.034$)$ & 0.719 & $0.022(-0.024$ to 0.034$)$ & 0.774 \\
\hline \multirow[t]{3}{*}{ Average $D_{f}$} & $\mathrm{HV}$ & SCZ & $0.247(0.02$ to 0.065$)$ & $<0.001$ & $0.285(0.026$ to 0.072$)$ & $<0.001$ \\
\hline & $\mathrm{HV}$ & $\mathrm{BD}$ & 0.307 (0.031 to 0.077$)$ & $<0.001$ & $0.342(0.037$ to 0.084$)$ & $<0.001$ \\
\hline & SCZ & $\mathrm{BD}$ & $0.068(-0.011$ to 0.035$)$ & 0.306 & $0.065(-0.011$ to 0.034$)$ & 0.323 \\
\hline
\end{tabular}

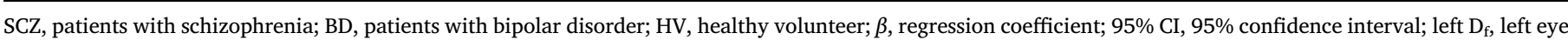
fractal dimension; right $\mathrm{D}_{\mathrm{f}}$, right eye fractal dimension; $\mathrm{D}_{\mathrm{f}}$, average fractal dimension. 
are required to understand whether the abnormalities in retinal vascular $\mathrm{D}_{\mathrm{f}}$ are progressive or not.

\subsection{Limitations}

Our findings need to be interpreted in the background of a few limitations. All patients were on pharmacological treatment and the effects of medications on $\mathrm{D}_{\mathrm{f}}$ is not known. 80 (82\%) out of $98 \mathrm{SCZ}$ patients and 48 (55\%) out of $87 \mathrm{BD}$ patients were taking atypical antipsychotic medications. As atypical antipsychotics are associated with increased metabolic risk in BD and SCZ (Vancampfort et al., 2013; Zhang et al., 2017) one cannot rule out the confounding effect of these medications on retinal vascular $\mathrm{D}_{\mathrm{f}}$. To examine the potential confounding effect of these medications, we examined the relation between retinal vascular $\mathrm{D}_{\mathrm{f}}$ and $\mathrm{CPZ}$ equivalents of antipsychotic medications using Pearson's correlation. Similarly, we examined the correlation between retinal vascular $D_{f}$ and duration of antipsychotic therapy. There was neither a significant correlation with antipsychotic dose (left Df: $r=0.02, p=0.85$; right $\mathrm{D}_{\mathrm{f}}: r=-0.14, p=0.12$; Average $\mathrm{D}_{\mathrm{f}}$ : $r=-0.08, p=0.36$ ) nor with duration of treatment (left $\mathrm{D}_{\mathrm{f}}: r=0.02$, $p=0.82$; right $\mathrm{D}_{\mathrm{f}}: r=-0.05, p=0.53$; Average $\mathrm{D}_{\mathrm{f}}: r=-0.02$, $p=0.78$ ) suggesting absence of significant confounding effect. Examining drug-naive patients could overcome this limitation and needs to be considered in future studies. As the participants were young, we excluded participants with hypertension, diabetes, and chronic renal disease based solely on history. Hence, sub clinical (pre-diabetic or prehypertensive) or undiagnosed hypertension/diabetes may have been missed (Benitez-Aguirre et al., 2011; Nguyen et al., 2007). However, we had measured BMI and blood pressure on the day of acquisition of images in a sub-sample and the results remained significant on analysing this sub-sample alone. Future studies need to consider recording blood pressure, fasting blood glucose, renal functions, and life style factors such as diet and exercise to complement image acquisition. Future studies also need to consider larger samples as the current sample was inadequate to perform sub-group analyses (e.g., BD-I vs BDII vs SCZ; BD with psychotic symptoms vs BD without psychotic symptoms vs SCZ etc.). As branching patterns of retinal arteries and veins are similar, and to avoid possible human error, we summarized the entire complexity of the retinal vascular structure into a single value of retinal vascular $D_{f}$. Future studies may consider examining the $D_{f}$ of arteries and veins separately.

\subsection{Conclusion}

This germinal study of retinal vascular $\mathrm{D}_{\mathrm{f}}$ in SCZ and BD suggests increased complexity of the retinal microvasculature branching pattern in SCZ and BD when compared to HV. There was no significant difference between SCZ and BD further supporting the shared pathophysiology and comorbidity in these disorders. Further prospective studies are needed to confirm these findings. However, these preliminary findings provide strong rationale to further examine retinal vascular fractal dimension in SCZ and BD. Considering the easy accessibility, non-invasive nature of examination, and affordability, the examination of retinal vascular $\mathrm{D}_{\mathrm{f}}$ could serve as a surrogate marker for abnormalities in cerebral vasculature. The findings of this preliminary study examining the retinal vascular $\mathrm{D}_{\mathrm{f}}$ in SCZ and BD need to be replicated in an independent sample for definitive scientific validation. If shown to be of predictive utility in future longitudinal studies, the examination of $\mathrm{D}_{\mathrm{f}}$ has the potential to identify BD and SCZ patients at risk of developing adverse vascular events.

\section{Declaration of Competing Interest}

Dr. Shyam Vasudeva Rao is Co-founder and Director at Forus Health Pvt Ltd, India. Other authors report no conflict of interest.

\section{CRediT authorship contribution statement}

Abhishek Appaji: Formal analysis, Writing - original draft, Data curation. Bhargavi Nagendra: Data curation, Formal analysis, Writing - original draft. Dona Maria Chako: Data curation. Ananth Padmanabha: Data curation, Formal analysis. Chaitra V. Hiremath: Data curation. Arpitha Jacob: Data curation. Shivarama Varambally: Conceptualization. Muralidharan Kesavan: Conceptualization. Ganesan Venkatasubramanian: Conceptualization. Shyam Vasudeva Rao: Conceptualization. Carroll A.B. Webers: Conceptualization. Tos T.J.M. Berendschot: Formal analysis, Writing original draft. Naren P. Rao: Formal analysis, Writing - original draft, Writing - review \& editing.

\section{Acknowledgements}

We thank Dr. Ami Sebastian for proof reading the manuscript.

\section{Funding Source}

Dr. Naren P. Rao is partially supported by the Department of Biotechnology, Ministry of Science and Technology, India- IYBA/2015/ 09. The funding agency did not have role in design of study or interpretation of results.

\section{Supplementary materials}

Supplementary material associated with this article can be found, in the online version, at doi:10.1016/j.jad.2019.08.061.

\section{References}

Aliahmad, B., Kumar, D.K., Hao, H., Unnikrishnan, P., Azemin, Che, M.Z., Kawasaki, R., Mitchell, 2014. Zone specific fractal dimension of retinal images as predictor of stroke incidence. Scientific World J. 2014, 467462.

Appaji, A., Nagendra, B., Chako, D.M., Padmanabha, A., Hiremath, C.V., Jacob, A., Varambally, S., Kesavan, M., Venkatasubramanian, G., Rao, S.V., Webers, C.A.B., Berendschot, T., Rao, N.P., 2019. Retinal vascular abnormalities in schizophrenia and bipolar disorder: a window to the brain. Bipolar Disord. https://doi.org/10.1111/bdi. 12779. Apr 22, [Epub ahead of print].

Benitez-Aguirre, P., Craig, M.E., Sasongko, M.B., Jenkins, A.J., Wong, T.Y., Wang, J.J., Cheung, N., Donaghue, K.C., 2011. Retinal vascular geometry predicts incident retinopathy in young people with type 1 diabetes: a prospective cohort study from adolescence. Diabetes Care 34, 1622-1627.

Brixey, S.N., Gallagher 3rd, B.J., McFalls Jr, J.A., Parmelee, L.F., 1993. Gestational and neonatal factors in the etiology of schizophrenia. J. Clin. Psychol. 49, 447-456.

Busner, J., Targum, S.D., 2007. The clinical global impressions scale: applying a research tool in clinical practice. Psychiatry (Edgmont) 4, 28-37.

Cabrera DeBuc, D., Somfai, G.M., Koller, A., 2017. Retinal microvascular network alterations: potential biomarkers of cerebrovascular and neural diseases. Am. J. Physiol. 312, H201-H212.

Cheung, C.Y., Thomas, G.N., Tay, W., Ikram, M.K., Hsu, W., Lee, M.L., Lau, Q.P., Wong, T.Y., 2012. Retinal vascular fractal dimension and its relationship with cardiovascular and ocular risk factors. Am. J. Ophthalmol. 154 (663-674), e661.

Cheung, N., Donaghue, K.C., Liew, G., Rogers, S.L., Wang, J.J., Lim, S.W., Jenkins, A.J., Hsu, W., Li Lee, M., Wong, T.Y., 2009. Quantitative assessment of early diabetic retinopathy using fractal analysis. Diabetes Care 32, 106-110.

Cheung, N., Liew, G., Lindley, R.I., Liu, E.Y., Wang, J.J., Hand, P., Baker, M., Mitchell, P., Wong, T.Y., Multi-Center, R., Stroke Study Collaborative, G., 2010. Retinal fractals and acute lacunar stroke. Ann. Neurol. 68, 107-111.

Cheung, N., Tikellis, G., Saw, S.M., Amirul Islam, F.M., Mitchell, P., Wang, J.J., Wong, T.Y., 2007. Relationship of axial length and retinal vascular caliber in children. Am. J. Ophthalmol. 144, 658-662.

Clarke, M.C., Harley, M., Cannon, M., 2006. The role of obstetric events in schizophrenia. Schizophr. Bull. 32, 3-8.

Correll, C.U., Solmi, M., Veronese, N., Bortolato, B., Rosson, S., Santonastaso, P., ThapaChhetri, N., Fornaro, M., Gallicchio, D., Collantoni, E., Pigato, G., Favaro, A., Monaco, F., Kohler, C., Vancampfort, D., Ward, P.B., Gaughran, F., Carvalho, A.F., Stubbs, B., 2017. Prevalence, incidence and mortality from cardiovascular disease in patients with pooled and specific severe mental illness: a large-scale meta-analysis of 3,211,768 patients and 113,383,368 controls. World Psychiatry 16, 163-180.

Craddock, N., Owen, M.J., 2010. The Kraepelinian dichotomy - going, going... but still not gone. Br. J. Psychiatry 196, 92-95.

Doubal, F.N., MacGillivray, T.J., Patton, N., Dhillon, B., Dennis, M.S., Wardlaw, J.M., 2010. Fractal analysis of retinal vessels suggests that a distinct vasculopathy causes lacunar stroke. Neurology 74, 1102-1107. 
Family, F., Masters, B.R., Platt, D.E., 1989. Fractal pattern formation in human retinal vessels. Physica D 38, 98-103.

Goldstein, B.I., 2017. Bipolar disorder and the vascular system: mechanisms and new prevention opportunities. Can. J. Cardiol. 33, 1565-1576.

Grimm, C., Willmann, G., 2012. Hypoxia in the eye: a two-sided coin. High Alt. Med. Biol. $13,169-175$.

Hamilton, M., 1960. A rating scale for depression. J. Neurol. Neurosurg. Psychiatry 23, $56-62$.

Huang, F., Dashtbozorg, B., Zhang, J., Bekkers, E., Abbasi-Sureshjani, S., Berendschot T.T., Ter Haar Romeny, B.M., 2016. Reliability of using retinal vascular fractal dimension as a biomarker in the diabetic retinopathy detection. J. Ophthalmol. 2016, 6259047.

Hudson, C.J., Lin, A., Cogan, S., Cashman, F., Warsh, J.J., 1997. The niacin challenge test: clinical manifestation of altered transmembrane signal transduction in schizophrenia? Biol. Psychiatry 41, 507-513.

Jones, S.H., Thornicroft, G., Coffey, M., Dunn, G., 1995. A brief mental health outcome scale-reliability and validity of the Global Assessment of Functioning (GAF). Br. J. Psychiatry 166, 654-659.

Kawasaki, R., Che Azemin, M.Z., Kumar, D.K., Tan, A.G., Liew, G., Wong, T.Y., Mitchell, P., Wang, J.J., 2011. Fractal dimension of the retinal vasculature and risk of stroke: a nested case-control study. Neurology 76, 1766-1767.

Kim, D.H., Newman, A.B., Hajjar, I., Strotmeyer, E.S., Klein, R., Newton, E., Sarnak, M.J., Burke, G.L., Lipsitz, L.A., 2011. Retinal microvascular signs and functional loss in older persons: the cardiovascular health study. Stroke 42, 1589-1595.

Knudtson, M., Klein, B., Klein, R., Wong, T., Hubbard, L., Lee, K., Meuer, S., Bulla, C., 2004. Variation associated with measurement of retinal vessel diameters at different points in the pulse cycle. Br. J. Ophthalmol. 88, 57-61.

Kostic, M., Bates, N.M., Milosevic, N., Tian, J., Smiddy, W.E., Lee, W.-H., Somfai, M. Márk, G., Feuer, W.J., Schiffman, J.C., 2018. Investigating the fractal dimension of the foveal microvasculature in relation to the morphology of the foveal avascular zone and to the macular circulation in patients with Type 2 diabetes mellitus. Front. Physiol. 9, 1233.

Lavina, B., 2016. Brain vascular imaging techniques. Int. J. Mol. Sci. 18.

Lesage, S.R., Mosley, T.H., Wong, T.Y., Szklo, M., Knopman, D., Catellier, D.J., Cole, S.R., Klein, R., Coresh, J., Coker, L.H., Sharrett, A.R., 2009. Retinal microvascular abnormalities and cognitive decline: the ARIC 14-year follow-up study. Neurology 73, $862-868$

Liew, G., Wang, J.J., Cheung, N., Zhang, Y.P., Hsu, W., Lee, M.L., Mitchell, P., Tikellis, G., Taylor, B., Wong, T.Y., 2008. The retinal vasculature as a fractal: methodology, reliability, and relationship to blood pressure. Ophthalmology 115, 1951-1956.

Lim, S.W., Cheung, N., Wang, J.J., Donaghue, K.C., Liew, G., Islam, F.M., Jenkins, A.J., Wong, T.Y., 2009. Retinal vascular fractal dimension and risk of early diabetic retinopathy: a prospective study of children and adolescents with type 1 diabetes. Diabetes Care 32, 2081-2083.

Mainster, M.A., 1990. The fractal properties of retinal vessels: embryological and clinical implications. Eye 4 (Pt 1), 235-241.

Masters, B.R., 2004. Fractal analysis of the vascular tree in the human retina. Annu. Rev. Biomed. Eng. 6, 427-452.

Mathew, R.J., Wilson, W.H., Tant, S.R., Robinson, L., Prakash, R., 1988. Abnormal resting regional cerebral blood flow patterns and their correlates in schizophrenia. Arch. Gen. Psychiatry 45, 542-549.

McGrory, S., Cameron, J.R., Pellegrini, E., Warren, C., Doubal, F.N., Deary, I.J., Dhillon, B., Wardlaw, J.M., Trucco, E., MacGillivray, T.J., 2017. The application of retinal fundus camera imaging in dementia: a systematic review. Alzheimer's Dementia 6, 91-107.

Meier, M.H., Gillespie, N.A., Hansell, N.K., Hewitt, A.W., Hickie, I.B., Lu, Y., McGrath, J., MacGregor, S., Medland, S.E., Sun, C., Wong, T.Y., Wright, M.J., Zhu, G., Martin, N.G., Mackey, D.A., 2015. Retinal microvessels reflect familial vulnerability to psychotic symptoms: a comparison of twins discordant for psychotic symptoms and controls. Schizophr. Res. 164, 47-52.

Meier, M.H., Hill, M.L., Breitborde, N.J.K., 2016. Retinal imaging: a new tool for studying underlying liability to cardiovascular disease in schizophrenia. Curr. Psychiatry Rev. 12, 326-334.

Meier, M.H., Shalev, I., Moffitt, T.E., Kapur, S., Keefe, R.S., Wong, T.Y., Belsky, D.W., Harrington, H., Hogan, S., Houts, R., Caspi, A, Poulton, R., 2013. Microvascular abnormality in schizophrenia as shown by retinal imaging. Am. J. Psychiatry 170, $1451-1459$.

Moss, H.E., 2015. Retinal vascular changes are a marker for cerebral vascular diseases. Curr. Neurol. Neurosci. Rep. 15, 40.

Naiberg, M.R., Hatch, J.K., Selkirk, B., Fiksenbaum, L., Yang, V., Black, S., Kertes, P.J., Goldstein, B.I., 2017. Retinal photography: a window into the cardiovascular-brain link in adolescent bipolar disorder. J. Affect. Disord. 218, 227-237.

Narrow, W.E., Clarke, D.E., Kuramoto, S.J., Kraemer, H.C., Kupfer, D.J., Greiner, L.,
Regier, D.A., 2013. DSM-5 field trials in the United States and Canada. Part III. Development and reliability testing of a cross-cutting symptom assessment for DSM5. Am. J. Psychiatry 170, 71-82.

Nguyen, T.T., Islam, F.M., Farouque, H.M., Klein, R., Klein, B.E., Cotch, M.F., Herrington, D.M., Wong, T.Y., 2010. Retinal vascular caliber and brachial flow-mediated dilation: the Multi-Ethnic Study of Atherosclerosis. Stroke 41, 1343-1348.

Nguyen, T.T., Wang, J.J., Wong, T.Y., 2007. Retinal vascular changes in pre-diabetes and prehypertension: new findings and their research and clinical implications. Diabetes Care 30, 2708-2715.

Overall, J.E., Gorham, D.R., 1962. The brief psychiatric rating scale. Psychol. Rep. 10, $799-812$.

Patton, N., Aslam, T., Macgillivray, T., Pattie, A., Deary, I.J., Dhillon, B., 2005. Retinal vascular image analysis as a potential screening tool for cerebrovascular disease: a rationale based on homology between cerebral and retinal microvasculatures. J. Anat. 206, 319-348.

Patton, N., Pattie, A., MacGillivray, T., Aslam, T., Dhillon, B., Gow, A., Starr, J.M., Whalley, L.J., Deary, I.J., 2007. The association between retinal vascular network geometry and cognitive ability in an elderly population. Invest. Ophthalmol. Vis. Sci. 48, 1995-2000.

Popovic, N., Radunovic, M., Badnjar, J., Popovic, T., 2018. Fractal dimension and lacunarity analysis of retinal microvascular morphology in hypertension and diabetes. Microvasc. Res. 118, 36-43.

Rubin, E., Sackeim, H.A., Prohovnik, I., Moeller, J.R., Schnur, D.B., Mukherjee, S., 1995 Regional cerebral blood flow in mood disorders: IV. Compar. Mania Depress. Psychiatry Res. 61, 1-10.

Sun, C., Wang, J.J., Mackey, D.A., Wong, T.Y., 2009. Retinal vascular caliber: systemic, environmental, and genetic associations. Surv. Ophthalmol. 54, 74-95.

Talu, S., Calugaru, D.M., Lupascu, C.A., 2015. Characterisation of human non-proliferative diabetic retinopathy using the fractal analysis. Int. J. Ophthalmol. 8, $770-776$.

Tamminga, C.A., Ivleva, E.I., Keshavan, M.S., Pearlson, G.D., Clementz, B.A., Witte, B., Morris, D.W., Bishop, J., Thaker, G.K., Sweeney, J.A., 2013. Clinical phenotypes of psychosis in the Bipolar-Schizophrenia Network on Intermediate Phenotypes (BSNIP). Am. J. Psychiatry 170, 1263-1274.

van de Kreeke, J.A., Nguyen, H.T., Konijnenberg, E., Tomassen, J., den Braber, A., Ten Kate, M., Sudre, C.H., Barkhof, F., Boomsma, D.I., Tan, H.S., Verbraak, F.D., Visser, P.J., 2018. Retinal and cerebral microvasculopathy: relationships and their genetic contributions. Invest. Ophthalmol. Vis. Sci. 59, 5025-5031.

Vancampfort, D., Vansteelandt, K., Correll, C.U., Mitchell, A.J., De Herdt, A., Sienaert, P., Probst, M., De Hert, M., 2013. Metabolic syndrome and metabolic abnormalities in bipolar disorder: a meta-analysis of prevalence rates and moderators. Am. J. Psychiatry 170, 265-274.

WHO, 1992. The ICD-10 Classification of Mental and Behavioural Disorders: Clinical descriptions and diagnostic guidelines. World Health Organization.

Witt, N., Wong, T.Y., Hughes, A.D., Chaturvedi, N., Klein, B.E., Evans, R., McNamara, M., Thom, S.A., Klein, R., 2006. Abnormalities of retinal microvascular structure and risk of mortality from ischemic heart disease and stroke. Hypertension 47, 975-981.

Wong, T.Y., Klein, R., Klein, B.E., Tielsch, J.M., Hubbard, L., Nieto, F.J., 2001. Retinal microvascular abnormalities and their relationship with hypertension, cardiovascular disease, and mortality. Surv. Ophthalmol. 46, 59-80.

Wong, T.Y., Klein, R., Sharrett, A.R., Nieto, F.J., Boland, L.L., Couper, D.J., Mosley, T.H., Klein, B.E., Hubbard, L.D., Szklo, M., 2002. Retinal microvascular abnormalities and cognitive impairment in middle-aged persons: the Atherosclerosis Risk in Communities Study. Stroke 33, 1487-1492.

Woods, S.W., 2003. Chlorpromazine equivalent doses for the newer atypical antipsychotics. J. Clin. Psychiatry 64 (6), 663-667.

Yanagi, M., Misumi, M., Kawasaki, R., Takahashi, I., Itakura, K., Fujiwara, S., Akahoshi, M., Neriishi, K., Wong, T.Y., Kiuchi, Y., 2014. Is the association between smoking and the retinal venular diameter reversible following smoking cessation? Invest. Ophthalmol. Vis. Sci. 55, 405-411.

Yau, J.W., Kawasaki, R., Islam, F.M., Shaw, J., Zimmet, P., Wang, J.J., Wong, T.Y., 2010. Retinal fractal dimension is increased in persons with diabetes but not impaired glucose metabolism: the Australian Diabetes, Obesity and Lifestyle (AusDiab) study. Diabetologia 53, 2042-2045.

Young, R.C., Biggs, J.T., Ziegler, V.E., Meyer, D.A., 1978. A rating scale for mania: reliability, validity and sensitivity. Br. J. Psychiatry 133, 429-435.

Zhang, Y., Liu, Y., Su, Y., You, Y., Ma, Y., Yang, G., Song, Y., Liu, X., Wang, M., Zhang, L., 2017. The metabolic side effects of 12 antipsychotic drugs used for the treatment of schizophrenia on glucose: a network meta-analysis. BMC Psychiatry 17, 373.

Zhu, P., Huang, F., Lin, F., Li, Q., Yuan, Y., Gao, Z., Chen, F., 2014. The relationship of retinal vessel diameters and fractal dimensions with blood pressure and cardiovascular risk factors. PLoS One 9, el06551. 